\title{
MEDIA NEOLOGISMS AS A FACTOR OF COMMUNICATIVE RISKS
}

\author{
Larisa V. Ratsiburskaya \\ National Research Lobachevsky State University of Nizhny Novgorod, Nizhny Novgorod, Russia \\ Darya V. Solovyeva \\ National Research Lobachevsky State University of Nizhny Novgorod, Nizhny Novgorod, Russia
}

\begin{abstract}
The paper analyzes media word creation in the context of its risk potential. On the basis of the modern socio-political press materials the author shows that unmotivated use of expressive neologisms can negatively affect the communication process and reduce its effectiveness: word-building neologisms can complicate the perception of a media text, distort the meaning of the information message, cause negative emotions in the recipient, lead to violation of ethical and aesthetic norms, etc. The risk potential of occasionalisms is considered in connection with their inherent and adherent expressiveness. The inherent expressiveness is stipulated by the structural and semantic features of the occasional words. Adherent expressiveness is connected with functional and discursive factors. The study of media neologisms allows not only identifying and characterizing the structural and functional features of the occasional lexemes, but also giving their social and ethical evaluation. It is necessary to draw attention of the linguistic community to the problem of communication risk potential since the consequence of communication risks can result in social, professional, political, and cultural risks. The research materials contribute to the further study of media discourse, word-formation neology and communication theory. They can also be used in the development of special courses for students of higher educational institutions, specializing in Journalism and Philology.
\end{abstract}

Key words: word-building neologisms, risk potential, communicative risks, expressiveness, media text.

Citation. Ratsiburskaya L.V., Solovyeva D.V. Media Neologisms as a Factor of Communicative Risks. Vestnik Volgogradskogo gosudarstvennogo universiteta. Seriya 2, Yazykoznanie [Science Journal of Volgograd State University. Linguistics], 2018, vol. 17, no. 4, pp. 81-89. (in Russian). DOI: https://doi.org/10.15688/jvolsu2.2018.4.7

\section{МЕДИЙНЫЕ НОВООБРАЗОВАНИЯ КАК ФАКТОР КОММУНИКАТИВНЫХ РИСКОВ}

\section{Лариса Викторовна Рацибурская}

Национальный исследовательский Нижегородский государственный университет им. Н.И. Лобачевского, г. Нижний Новгород, Россия

\section{Дарья Владимировна Соловьева}

Национальный исследовательский Нижегородский государственный университет им. Н.И. Лобачевского, г. Нижний Новгород, Россия

Аннотация. В статье анализируется медийное словотворчество в аспекте его рискогенности. На материале публикаций в современной общественно-политической прессе показано, что немотивированное использование экспрессивных новообразований может отрицательно отражаться на процессе коммуникации, его эффективности: словообразовательные неологизмы способны затруднять восприятие медиатекста, искажать смысл информационного сообщения, вызывать у адресата негативные эмоции, приводить к наруше- 


\section{РАЗВИТИЕ И ФУНКЦИОНИРОВАНИЕ РУССКОГО ЯЗЫКА}

нию этических и эстетических норм и др. Рискогенность окказионализмов рассматривается в связи с их ингерентной и адгерентной экспрессивностью. Ингерентная экспрессивность обусловлена структурно-семантическими особенностями окказиональных слов. Адгерентная экспрессивность связана с функционально-дискурсивными факторами. Изучение медийных новообразований позволяет не только выявить и описать структурные и функциональные особенности окказиональных лексем, но и дать им социально-этическую оценку. Привлечение внимания лингвистического сообщества к проблеме рискогенности коммуникации необходимо потому, что следствием коммуникативных рисков могут стать риски социального, профессионального, политического, культурного характера. Материалы исследования вносят вклад в дальнейшее изучение медийного дискурса, словообразовательной неологии и теории коммуникации. Они также могут быть использованы в разработке спецкурсов для студентов высших учебных заведений, обучающихся по направлениям «Филология» и «Журналистика».

Ключевые слова: словообразовательные неологизмы, рискогенность, коммуникативные риски, экспрессивность, медиатекст.

Цитирование. Рацибурская Л. В., Соловьева Д. В. Медийные новообразования как фактор коммуникативных рисков // Вестник Волгоградского государственного университета. Серия 2, Языкознание. - 2018. T. 17, № 4. - C. 81-89. - DOI: https://doi.org/10.15688/jvolsu2.2018.4.7

\section{Введение}

Коммуникация - одна из основ жизни общества - с лингвистической точки зрения понимается как «процесс передачи сообщения адресантом и его восприятия адресатом при использовании ими одного и того же языка (мимика, жесты, позы и окружающие предметы - добавочные, вспомогательные, но не основные средства коммуникации, как ее знаки они изучаются в семиотике и криминалистике)» [Рискогенность современной коммуникации..., 2015, с. 10].

Выявляя критерии успешной коммуникации, пристальное внимание к которой обусловлено возросшим интересом к функциональным и прагматическим аспектам речи, многие ученые (Т.М. Дридзе, Е.А. Земская, О.В. Кукушкина, Н.И. Формановская) указывают на проблемы - сбои или провалы - в процессе общения. В теории коммуникации возникли такие понятия, требующие осмысления, как коммуникативные неудачи, коммуникативные барьеры, коммуникативные риски.

Исследованию коммуникативных неудач (КН) посвящено большое количество лингвистических работ, в которых подчеркивается, что КН являются «почти неизбежными спутниками естественного общения» [Гудков, 2003, c. 12]. Этим термином обозначается «полное или частичное непонимание высказывания партнером коммуникации, то есть неосуществление или неполное осуществление коммуникативного намерения говорящего» [Ермакова, Земская, 1993, с. 30-31]. Анализируя специфику данного явления на материале естественного русского диалога, авторы процитированной работы одним из видов КН считают также «нежелательный эмоциональный эффект, не предусмотренный говорящим в процессе общения: обида, раздражение, изумление» [Ермакова, Земская, 1993, с. 32]. Н.И. Формановская выделяет социально-культурные, психосоциальные и собственно языковые КН [Формановская, 2002]. Объединяет все виды коммуникативных неудач их свойство быть обнаруженными непосредственно в процессе общения, когда коммуниканты не предполагают их возникновения.

Этим КН отличаются от коммуникативных барьеров (КБ), которые осознаются участниками общения как препятствие для эффективной коммуникации еще до ее начала. КБ могут быть связаны с факторами окружающей среды (акустические помехи, погодные условия), с техническими факторами (плохое качество связи, помехи в эфире), с человеческими факторами (психологические, социокультурные, эмоциональные барьеры и др.).

Термин «коммуникативные риски» (КР) в трудах лингвистов появился сравнительно недавно и не имеет еще словарной дефиниции. Типология КР, представленная в работе саратовских исследователей, основана на упомянутой классификации КН: выделяются риски полного непонимания, неправильного / неполного или не совсем точного понимания, а также риски вызова у адресата нежелательной эмоциональной реакции [Рискогенность современной коммуникации..., 2015]. На наш 
взгляд, сущность термина-словосочетания заключена в семантической характеристике главного слова: риск - 'реальная возможность чего-либо нежелательного, опасного' (БУСРЯ, с. 1018). Исходя из этого, сформулируем рабочее определение нового термина: коммуникативный риск - это реальная возможность получения непрогнозируемого, нежелательного результата коммуникации, возможность возникновения коммуникативной неудачи.

В живом общении КН - это свершившийся факт, а КР - это потенциальная возможность КН, создаваемая особенностями речи и коммуникативного поведения участников общения, условиями коммуникации. Следовательно, участники общения могут преодолеть риски в случае их идентификации (например, эмоциональная реакция адресата на утверждение). В письменной речи (в частности, в сфере СМИ) предупредить КР гораздо сложнее, так как между адресантом и адресатом нет непосредственной обратной связи. Следствием неопознанных КР в массовой печати могут стать риски социального, профессионального, политического, культурного и иного характера.

\section{Специфика экспрессивности неологизмов в СМИ}

Коммуникативная функция является исходной функцией журналистики - это «функция общения, налаживания контакта» [Прохоров, 2011, с. 59]. Она реализуется в тройном информационном взаимодействии: налаживание связей между субъектами журналистики, массовой аудиторией и важнейшими социальными институтами. Только после установления таких контактов возможно выполнение других функций, прежде всего воздействующей.

Одной из зон КР в медиакоммуникации является словообразовательная система языка, в частности, ее речевая реализация в виде новообразований. С одной стороны, новообразования в СМИ обладают неисчерпаемым экспрессивным потенциалом, являются эффективным средством воздействия на массовую аудиторию, отражают актуальные процессы в жизни общества. Экспрессивность исследователи выделяют как внутренний, из- начально присущий авторскому новообразованию признак: «Обязательная экспрессивность - характернейшая черта окказиональных слов. Это их сквозной признак, в отличие от слов канонических, большей части которых экспрессивность не свойственна» [Лыков, 1976, с. 23]. С другой стороны, употребление новообразований в текстах СМИ способно вызывать сложности восприятия, провоцировать сбои в коммуникации, приводить к нарушению морально-этических принципов и др.

Сегодня прагматической установкой на воздействие характеризуется фактически любой журналистский текст, специфической чертой которого является оценочность - «совокупность разноуровневых языковых единиц, объединенных оценочной семантикой и выражающих положительное или отрицательное отношение автора к содержанию речи» [Баженова, 2003, с. 139]. Понятие оценочности взаимодействует с понятием экспрессивности, и в работах многих лингвистов они отождествляются. Однако эти понятия имеют существенные различия: оценочность - это частный признак экспрессивности, которая связана с воздействующей (прагматической) функцией языковых единиц. Их основное предназначение - «не просто назвать тот или иной элемент действительности, а сделать это так, чтобы воздействовать на собеседника, причем вторая задача выходит на первый план» [Кругликова, 1988, с. 53].

Нецелесообразное использование экспрессивных средств языка, обусловленное стремлением авторов максимально воздействовать на читателя, способствует появлению КР в медийном дискурсе: «Часто участники общения ищут какие-то броские, необычные языковые средства, выражения своих мыслей, позволяющие им выделиться, любой ценой заставить обратить на себя внимание. Но поиски необычного в общении в условиях беспредельной свободы при недостаточном уровне коммуникативной компетенции приводят порой к ухудшению качества передаваемого сообщения» [Рискогенность современной коммуникации..., 2015, с. 44].

Употребление оценочных окказионализмов может стать причиной возникновения КР, однако это не означает, что каждое оценочное новообразование рискогенно, то есть спо- 


\section{РАЗВИТИЕ И ФУНКЦИОНИРОВАНИЕ РУССКОГО ЯЗЫКА}

собно порождать риск, например, «упрек, осуждение, критический анализ, критические замечания сами по себе представляют нормальное явление, если они обоснованы и выражаются адекватными ситуации средствами» [Петрова, Рацибурская, 2011, с. 20]. Вместе с тем в современных СМИ нередки такие случаи медийного словотворчества, которые могут отрицательно отражаться на коммуникативном процессе, препятствовать реализации коммуникативного намерения (интенции) автора. При анализе подобных случаев важно не только указать потенциально «опасные» новообразования, но и определить, чем обусловлена их рискогенность.

\section{Ингерентная экспрессивность неологизмов как фактор их рискогенности}

Оценочный характер словообразовательных неологизмов может зависеть от их структурных особенностей: в состав нового слова входит экспрессивный формант или словообразовательная основа, оно создано с использованием экспрессивного способа словообразования (контаминация, заменительная деривация и др.), принадлежит словообразовательному типу с экспрессивным значением. В таких случаях ученые говорят об ингерентной, то есть не зависящей от контекста, экспрессии:

(1) Шифрофрения. Мессенджеры готовят к вскрытию (Коммерсант, 04.10.2016);

(2) ОтЦБятина. Банк России пока не сильно помогает экономике страны (Наша Версия, 04.09.2016);

(3) Сейсмофига. В стране продолжают закрывать сейсмостанции и увольнять специалистов (Наша Версия, 04.09.17).

Новообразование шифрофрения возникло как результат контаминации иифрование + иизофрения; отЦБятина (от отсебятина), сейсмофига (от сейсмостанция) - как результат заменительной деривации. Рискогенность представленных новообразований-гибридов (риск спровоцировать нежелательную читательскую реакцию) связана с негативнооценочной семантикой отдельных производящих слов - иизофрения, отсебятина, фига. Субъект коммуникации намеренно пытается вызвать у адресата негативные эмоции, заменяя конструктивную критику обвинением, порицанием, оскорблением. Это может привести к повышению уровня агрессивности в общественном пространстве.

Сочетаемость сразу нескольких структурных особенностей обусловила высокий уровень экспрессивности в следующем примере:

(4) ДоБАЗАрились. Не разорит ли Россию строительство военных баз за границей (Наша Версия, 14.01.2018).

Выбранный автором словообразовательный тип, реализующий значение 'довести себя до неприятных последствий путем интенсивного совершения действия, названного мотивирующим глаголом' (доработаться, добегаться и пр.) [Русская грамматика, т. I, с. 384], представлен преимущественно в разговорной речи; мотивирующим для окказионализма является стилистически сниженный глагол $б a-$ зарить (жарг. 'говорить'). Смысловая связь окказионализма с тематикой статьи устанавливается благодаря графической акцентуации слова база.

Появление в СМИ жаргонной, вульгарной и бранной лексики вызывает этическую настороженность в социуме. Об этом писал еще Б.Н. Головин: «Чистой мы называем такуюречь, в которой нет чуждых литературному языку элементов и нет элементов языка, отвергаемых нормами нравственности» [Головин, 1981, с. 18]. Недопустимыми с этой точки зрения являются следующие новообразования:

(5) Аккуеть! (Наша Версия, 22.08.16).

В материале говорится о строительстве в Турции атомной электростанции Аккую, наименование которой и положено в основу окказионального слова;

(6) АУЕвшие малолетки. У детей входит в моду жизнь по тюремным понятиям (Наша Версия, 28.08.17),

графический гибрид мотивирован малоизвестной аббревиатурой АУЕ (Арестантский уклад един), обозначающей неформальное объединение молодежи в современной России. В данных примерах наблюдается синтез сразу двух коммуникативных рисков: слож- 
Л.В. Рацибурская, Д.В. Соловьева. Медийные новообразования как фактор коммуникативных рисков

ность восприятия статьи и прямое нарушение законов успешной коммуникации (унижение собеседника), так как окказионализмы явно неблагозвучны, имеют фонетическое сходство с бранными выражениями. Эксплицитная оценка создается посредством использования грубых, непристойных выражений. Журналисты не считаются с нравственными законами, изобретая новые слова, что может дискредитировать образ самих создателей текста в глазах общественности, а также навредить имиджу изданий в целом.

Структурные особенности новых слов приводят к рискам, связанным не только с неуместной экспрессией, но и с непониманием смысла окказиональной лексемы. Адресат может неправильно «расшифровать код», информация будет воспринята искаженно или вовсе останется неусвоенной. Так, в результате журналистской небрежности не только усложняется понимание текста, но и происходит дезориентация массового адресата в информационном потоке:

(7) КОИБания (КОИБ + колебания) с линией партии. Как ЦИК создает политические проблемы из обычного разгильдяйства (Новая газета, 11.03.2018).

Сложность для понимания окказионализма связана с определением денотата мотивирующего слова - редкой аббревиатуры КОИБ (Комплекс обработки избирательных бюллетеней).

За неясностью авторского замысла может стоять немотивированное включение в словообразовательные игры иноязычных элементов. Журналисты злоупотребляют малоизвестными заимствованными лексемами, транслитерированными иноязычными элементами:

(8) «Восстание фейкометов». Ополченцев Донбасса выдали за погибших в Сирии «вагнеровцев» (Наша Версия, 22.02.2018),

новое слово образуется от неологизма фейк (англ. fake - 'подделка') и служит для обозначения людей, которые распространяют в интернете заведомо ложную информацию;

(9) Но остальные национал-социалисты спокойно продолжили путь вместе с либералами и лефтишами (Завтра, 25.02.2018);
(10) А барыга, закупающий паленый кажуальный шмот на «Али-экспрессе» и перепродающий его со стопроцентной накруткой тем, кто не догадался сам залезть в интернет, они своих клиентов презирают (МК, 26.03.2018).

Окказионализмы образованы от английских слов left ('левый'), casual ('повседневный').

Стремление «быть в тренде» может обернуться для авторов реальным коммуникативным провалом: у читателей возникнет чувство неполноценности, ущербности, тревоги при попытке осмыслить написанное.

Заимствованные слова, используемые до их реального вхождения в лексическую систему русского языка, являются потенциальными «рискогенами», их употребление в медиатекстах требует грамотных авторских пояснений:

(11) Накраудфанди наудачу (АиФ, 18.01.2018).

Императивный глагол мотивирован англицизмом краудфандинг. Журналист пишет: В 2018-м «узаконят» ещзе один модный, но пока не очень известный в России способ вложения денег - краудфандинг, то есть «организацию взаимного финансирования». Поясняется, что это за явление, однако почему популярный способ вложения денег назван именно так, станет понятно только читателям, владеющим английским языком (англ. crowdfunding - 'народное финансирование', crowd - 'толпа').

Перенасыщение медийных текстов иноязычной лексикой вызывает тревогу лингвистического сообщества: «Одна из распространенных стратегий негативного воздействия на адресата речи - это создание кодового конфликта: через разницу кодов адресант, стараясь унизить адресата, сознательно стремится к непониманию $<. .>$. ...используется узкоспециальная терминология и, прежде всего, варваризмы - малоизвестные заимствования, иноязычные вкрапления» [Коряковцева, 2008, с. 97].

\section{Адгерентная экспрессивность неологизмов как фактор их рискогенности}

Коммуникативные риски, порождаемые окказиональными лексемами, также необходимо рассматривать в связи с адгерентной 


\section{РАЗВИТИЕ И ФУНКЦИОНИРОВАНИЕ РУССКОГО ЯЗЫКА}

(внешней, приобретенной) экспрессией новообразований. В большинстве случаев она как бы наслаивается на ингерентную экспрессию, дополняет ее. Адгерентная экспрессивность окказионализмов создается за счет их лексического и контекстуального окружения, тематической направленности материалов, использования в словообразовании ключевых слов эпохи, прецедентных феноменов. Это так называемые функционально-дискурсивные факторы экспрессивности окказиональных слов.

В следующем заголовке окказионализм создается по образцу голофрастического новообразования Крымнаш, пользующегося популярностью в материалах прессы об украинских событиях:

(12) Крымкэш. «Сакральная Корсунь» рискует превратиться в «хаб» для обналички и других незаконных банковских операций (Новая газета, 01.06.2015).

Первый риск возникает в результате усложнения восприятия за счет использования в новообразовании английской лексемы кэш (англ. cash - 'наличные деньги'). Вторая опасность связана с контекстуальным окружением: если универб обналичка ('незаконный перевод безналичных денежных средств в наличные') широко распространен в разговорной речи, то малознакомое широкой аудитории слово из компьютерного жаргона хаб (жарг. 'сетевой концентратор'), вероятно, вызовет нежелание адресанта знакомиться с текстом.

Проблемы интерпретации окказионального слова возникают не только в тех случаях, когда речь идет о словах, мотивированных англицизмами:

(13) Раскуначили! Проворовавшимся региональным элитам впору заказывать себе тюремные робы (Наша Версия, 11.02.2018).

Замена корня в узуальном раскулачили на созвучный экзотизм кунак: у кавказских горцев 'лицо, связанное с кем-либо обязательством взаимной дружбы, защиты, гостеприимства; друг, приятель' (БТСРЯ, с. 480). Используя выразительные возможности слова, имеющего территориальную принадлежность, автор рискует вызвать недоумение аудитории. Кроме того, окказионализм раскуначили ас- социируется с бранными словами: именно грубо-экспрессивный потенциал слова станет определяющим для тех читателей, которым производящее слово неизвестно. Уровень отрицательной оценки повышается за счет контекста, в котором употреблены новообразования с суффиксом -щин-, имеющим семантику неодобрения:

(14) По сути, в республике складывалась клановая кумовщина, точнее, кунакщина, с круговой порукой, замешанной на самой неприкрытой коррупции (Наша Версия, 11.02.2018).

Журналист напрямую обвиняет тех, кто стал объектом его профессионального внимания. Нарушение моральных принципов не просто может препятствовать коммуникативному процессу, но и спровоцировать риски юридического характера - возможность возникновения судебного конфликта.

Как известно, на распространение в общественном пространстве антипатриотических взглядов нацелены журналисты оппозиционных изданий:

(15) Игры патриастов. Военно-спортивная игра «Зеленка» может привести к необратимым последствиям (Новая газета, 29.04.2017).

Окказионализм образуется путем междусловного наложения узуального патриот и вульгарного педераст - 'тот, кто предается педерастии' (БТСРЯ, с. 789). Коммуникативные риски возникают потому, что, во-первых, интеллектуальных усилий от читателя требует «дешифровка» новообразования, провести которую возможно только после знакомства с материалом; во-вторых, отталкивает пейоративная коннотация нового слова, неприемлемая для интеллигентной аудитории, в-третьих, смысловую сумятицу вносит в текст употребление других новообразований:

(16) Так что с Варламовым все очевидно. Тут долгая, безнаказанная, все контролирующая цапковщина в полный рост и полная уверенность духовно-патриотичных цапков (Новая газета, 29.04.2017).

Словообразовательные неологизмы мотивированы именем собственным, которое сегодня уже неактуально для массового читателя (Сергей Цапок - лидер организованной пре- 
Л.В. Рацибурская, Д.В. Соловьева. Медийные новообразования как фактор коммуникативных рисков

ступной группировки в России; осужден в ноябре 2013 года).

Рискогенными следует признать игровые окказиональные лексемы (особенно в заголовочных комплексах) в материалах о трагических событиях:

(17) \#Мосхозсмерть. «Наша Версия» продолжает расследование гибели ветерана в «Мосхозторге» (Наша Версия, 31.03.2018).

Часть узуального Мосхозторг заменена на существительное смерть, вызывающее у адресата негативные эмоции. Тематика материала не согласуется с пренебрежительной иронией, которую содержит индивидуальноавторское слово.

Циничным является заголовок материала, в котором говорится о последствиях страшного пожара в торговом центре «Зимняя вишня»:

(18) ЧОПнулись по-быстрому. Охранная фирма, отвечавшая за безопасность в ТЦ «Зимняя вишня», самоликвидировалась (Наша Версия, 30.03.2018).

Автор нарушает все нормы нравственности, образуя графодериват на базе аббревиатуры ЧОП (частное охранное предприятие) и омонимичного сленгизма чпокнуться (по-быстрому) (сленг. 'провести ночь с кем-то'). Читателей не может не возмутить такая эпатажная языковая игра, они осудят авторское стремление «быть оригинальным» при описании человеческих драм.

Оскорбительным, неприемлемым для всех членов социума может быть следующий заголовок:

(19) Легкое сдыхание (сдыхать + дыхание). От грязного воздуха каждый год умирают 140 тысяч россиян (Наша Версия, 15.01.2018).

Использование грубого новообразования при подаче драматических статистических данных не способствует гармоничному общению с читателями, может оказать на аудиторию угнетающее воздействие. У начитанных людей возникает ассоциация со знаменитым рассказом И.А. Бунина «Легкое дыхание», однако, кроме трагичности тем статьи и художественного произведения, никаких связей между ними больше не прослеживается.
Неудачное использование прецедентных феноменов часто снижает информативность заголовочного комплекса:

(20) Керри-бредни, ангел мой (Завтра, $01.05 .2015)$

В названии журналистского материала обыгрывается строчка из стихотворения Осипа Мандельштама (Шерри-бренди, ангел мой) и имя американского политика (Джсон Кер$p u)$. Шуточный тон при освещении серьезных проблем является неуместным, материалы вряд ли заинтересуют компетентных читателей, хотя нацелены они именно на них. Прецедентные феномены обусловливают двусмысленность в понимании текста, хотя обоснованной логической связи между именами собственными и используемыми выражениями нет. Вероятно, прецеденты случайно вызвали индивидуальные эмоциональные ассоциации у авторов статей.

\section{Выводы}

Словообразовательные неологизмы, создавая возможность нереализации прогнозируемого авторского намерения, возможность провала, сбоя коммуникации, порождают коммуникативные риски.

Лингвистический анализ новообразований позволяет установить, как создается рискогенность новообразований, а последствия рискогенных словоупотреблений представляют научный интерес в социолингвистическом аспекте. Рискогенность окказиональных новообразований может быть связана с их структурно-семантическими особенностями или обусловлена различными дискурсивными факторами (контекстуальным и лексическим окружением, актуализацией фоновых знаний реципиента и пр.).

В большинстве случаев использование окказиональных лексем, в основе которых лежит жаргонная, вульгарная, обсценная лексика, можно признать рискогенным. Такие новообразования негативно воздействуют на массовую аудиторию, могут провоцировать ответную агрессию, часто дезориентируют массового читателя в информационном потоке. Результаты проведенного анализа нагляд- 


\section{РАЗВИТИЕ И ФУНКЦИОНИРОВАНИЕ РУССКОГО ЯЗЫКА}

но демонстрируют также опасность избыточного употребления заимствований в публикациях СМИ. Включение «импортных» слов в словообразовательные эксперименты может отрицательно влиять на речевую культуру аудитории, угрожать национальной самобытности русского языка. На рискогенность неологизмов, связанную с их экспрессивностью, существенное влияние оказывают дискурсивные факторы. Нередко контекст, а также обращение журналиста к культурным и фоновым знаниям аудитории не облегчают восприятие новообразований, а усложняют его, свидетельствуют об агрессивном речевом поведении автора, нарушении им этических и эстетических табу, приводят к возникновению неоправданных и избыточных ассоциаций, затемняющих понимание основного смысла статьи.

\section{СПИСОК ЛИТЕРАТУРЫ}

Баженова Е. А., 2003. Стилистический энциклопедический словарь русского языка / под ред. М. Н. Кожиной. М. : Флинта : Наука. С. 139-146.

Головин Б. Н., 1981. О хорошей речи // О культуре речи : сб. ст. М. : Знание. С. 3-68.

Гудков Д. Б., 2003. Теория и практика межкультурной коммуникации. М. : ИТДГК «Гнозис». 288 с.

Ермакова Е. Н., Земская Е. А., 1993. К построению типологии коммуникативных неудач // Русский язык в его функционировании. Коммуникативно-прагматический аспект. М. : Наука. С. 30-64.

Коряковцева Е. И., 2008. Язык современной российской прессы: варваризмы и арготизмы как сигналы речевой агрессии // Prace slawistyczne. 125: Współczesna komunikacja językowa : najnowsze zmiany w leksyce i słowotwórstwie języków słowiańskich / red. nauk. Zofia RudnikKarwatowa. Warszawa : Slawistyczny ośrodek wydaw. S. 80-110.

Кругликова Л. Е., 1988. Структуры лексического и фразеологического значения. М. : МГПИ им. В.И. Ленина. 86 с.

Лыков А. Г., 1976. Современная русская лексикология (русское окказиональное слово). М. : Высшая школа. $120 \mathrm{c}$.

Петрова Н. Е., Рацибурская Л. В., 2011. Язык современных СМИ: средства речевой агрессии. М. : Флинта : Наука. 160 с.

Прохоров Е. П., 2011. Введение в теорию журналистики. М. : Аспект Пресс. 351 с.

Рискогенность современной коммуникации..., 2015. Рискогенность современной коммуникации и роль коммуникативной компетентности в ее преодолении / А. Н. Байкулова [и др.] ; под ред. О. Б. Сиротининой и М. А. Кормилицыной. Саратов : Изд-во Сарат. ун-та. 188 с.

Русская грамматика, 1980. Русская грамматика : в 2 т. Т. 1. М. : Наука. 789 с.

Формановская Н. И., 2002. Речевое общение: коммуникативно-прагматический подход. М. : Русский язык. 216 с.

\section{ИСТОЧНИКИ}

АиФ-«Аргументы и Факты». URL: http:/www.aif. ru. Завтра - «Завтра». URL: http://zavtra.ru.

Коммерсант - «Коммерсант». URL: https://www. kommersant.ru.

$M K$ - «Московский Комсомолец». URL: http://mk.ru. Наша Версия - «Наша Версия». URL: https://versia. ru. Новая газета - «Новая газета». URL: https://www. novayagazeta.ru.

\section{СЛОВАРИ}

БТСРЯ - Большой толковый словарь русского языка / сост. и гл. ред. С. А. Кузнецов. СПб. : Норинт, 2000. $1536 \mathrm{c}$.

БУСРЯ - Большой универсальный словарь русского языка / под ред. В. В. Морковкина. М. : Словари XXI века ; АСТ-ПРЕСС ШКОЛА, 2016. $1456 \mathrm{c}$.

\section{REFERENCES}

Bazhenova E.A., 2003. The Stylistic Encyclopedic Dictionary of the Russian Language. Moscow, Flinta; Nauka Publ., pp. 139-146.

Golovin B.N., 1981. On Good Speech. O kulture rechi: sb. statey. Moscow, Znanie Publ., pp. 3-68.

Gudkov D.B., 2003. Theory and Practice of Intercultural Communication. Moscow, Gnozis Publ. 288 p.

Ermakova E.N., Zemskaya E.A., 1993. Towards a Typology of Communicative Failures. Russkiy yazykv ego funktsionirovanii. Kommunikativnopragmaticheskiy aspekt. Moscow, Nauka Publ., pp. 30-64.

Koryakovtseva E.I., 2008. The Language of the Modern Russian Press: Barbarisms and Slang as Signals of Speech Aggression. RudnikKarwatowa Z., ed. Prace slawistyczne. 125: Współczesna komunikacja językowa: najnowsze zmiany $w$ leksyce $i$ stowotwórstwie języków stowiańskich. Warszawa, Slawistyczny ośrodek wydaw, pp. 80-110. 
Л.В. Рацибурская, Д.В. Соловьева. Медийные новообразования как фактор коммуникативных рисков

Kruglikova L.E., 1988. Structures of Lexical and Phraseological Meaning. Moscow, MGPI im. V.I. Lenina. $86 \mathrm{p}$.

Lykov A.G., 1976. Modern Russian Lexicology (Russian Occasional Word). Moscow, Vysshaya shkola Publ. 120 p.

Petrova N.E., Ratsiburskaya L.V., 2011. The Language of Modern Mass Media: Means of Speech Aggression. Moscow, Flinta; Nauka Publ. 160 p.

Prokhorov E.P., 2011. Introduction to the Theory of Journalism. Moscow, Aspect Press. 351 p.

Baykulova A.N., Viktorova E.Yu. (et al.), 2015. The Risk Potential of Modern Communication and the Role of Communicative Competence in Overcoming It. Saratov, Izd-vo Sarat. un-ta. $188 \mathrm{p}$.

Russian Grammar. In 2 vols. Moscow, Nauka Publ., 1980, vol. 1. 789 p.

Formanovskaya N.I., 2002. Speech Communication: a Communicative-Pragmatic Approach. Moscow, Russkiy yazyk Publ. 216 p.

\section{SOURCES}

Newspaper Argumenty i fakty. URL: http://www.aif.ru/. Newspaper Zavtra. URL: http://zavtra.ru/.

Newspaper Kommersant. URL: https://www. kommersant.ru/.

Newspaper Moskovskiy Komsomolets. URL: http:// mk.ru/.

Newspaper Nasha Versiya. URL: https://versia.ru/.

Newspaper Novaya gazeta. URL: https://www. novayagazeta.ru/.

\section{DICTIONARIES}

Kuznetsov S.A. (ed.), 2000. The Big Explanatory Dictionary of the Russian Language. Saint Petersburg, Norint Publ. $1536 \mathrm{p}$.

Morkovkin V.V. (ed.), 2016. The Big Universal Dictionary of the Russian Language. Moscow, Slovari XXI veka; AST-PRESS SHKOLA Publ. $1456 \mathrm{p}$.

\section{Information about the Authors}

Larisa V. Ratsiburskaya, Doctor of Sciences (Philology), Professor, Head of Department of Modern Russian Language and General Linguistics, Institute of Philology and Journalism, National Research Lobachevsky State University of Nizhny Novgorod, Prosp. Gagarina, 23, 603950 Nizhny Novgorod, Russia, racib@yandex.ru, https://orcid.org/0000-0002-9332-050X

Darya V. Solovyeva, Postgraduate Student, Department of Modern Russian Language and General Linguistics, Institute of Philology and Journalism, National Research Lobachevsky State University of Nizhny Novgorod, Prosp. Gagarina, 23,603950 Nizhny Novgorod, Russia, solovyova_dariya@mail.ru, https://orcid.org/0000-0003-1727-0034

\section{Информация об авторах}

Лариса Викторовна Рацибурская, доктор филологических наук, профессор, заведующая кафедрой современного русского языка и общего языкознания, Институт филологии и журналистики, Национальный исследовательский Нижегородский государственный университет им. Н.И. Лобачевского, просп. Гагарина, 23, 603950 г. Нижний Новгород, Россия, racib@yandex.ru, https://orcid.org/0000-0002-9332-050X

Дарья Владимировна Соловьева, аспирант кафедры современного русского языка и общего языкознания, Институт филологии и журналистики, Национальный исследовательский Нижегородский государственный университет им. Н.И. Лобачевского, просп. Гагарина, 23, 603950 г. Нижний Новгород, Россия, solovyova_dariya@mail.ru, https://orcid.org/0000-0003-1727-0034 